\title{
Wittgenstein, la filosofía del concepto y la estrategia de su filosofía ${ }^{1}$
}

\author{
Pedro Karczmarcsyle*
}

\begin{abstract}
Resumen: El par "filosofía del concepto" y "del sujeto" distingue posiciones contemporáneas respecto a la fundamentación filosófica. Las primeras, al concebir al sujeto como un efecto, suponen una transformación radical de la labor filosófica. Como Lecourt ha mostrado, el Tractatus combate contra la concepción de la filosofía como un discurso de unificación y fundamentación, suponiendo que este discurso produce primero una herida (entre pensamiento y ser), para cicatrizarla luego con un discurso que garantiza el contacto entre los dominios instaurados por la herida. La ausencia de dudas sobre el significado puso al Tractatus en la senda de un razonamiento regresivo, que no devino trascendental por la imposibilidad del metalenguaje. Las Investigaciones filosóficas advirtieron que este embate estaba todavía cautivo de un objeto filosófico, el significado, e intentaron eliminarlo mostrando cómo el mismo se destruye al entrar en contacto con la áspera práctica del lenguaje. La carencia de dudas ya no será el índice de un "saber" semántico fundamental, sino un elemento constitutivo de la práctica de los juegos de lenguaje, donde funciona como un requisito impuesto a los hablantes para detentar su condición de tales, aproximándolo a la concepción de la ideología desarrollada por Althusser. Concluimos mostrando algunos límites del pensamiento de Wittgenstein que su inclusión en la categoría de la filosofía del concepto habilita reconocer.
\end{abstract}

\footnotetext{
${ }^{1}$ Una versión anterior de este trabajo fue presentada en las "V Jornadas de filosofía del conocimiento" en la Facultad de Humanidades, de la Universidad Nacional de La Plata, 21-23 de agosto de 2016, agradezco las preguntas y discusiones de los asistentes a la misma.

* Profesor, Licenciado y Doctor en Filosofía por la Universidad Nacional de La Plata. En esta institución se desempeña como Profesor Adjunto a cargo de Filosofía Contemporánea. Es Investigador Adjunto de CONICET. Ha publicado dos libros, compilado otros dos y se ha desempeñado como editor de números especiales de revistas. Ha publicado artículos en revistas especializadas, argentinas y del exterior. Dirección electrónica: pedrokarcz@,hotmail.com
} 
Palabras clave: Wittgenstein, filosofía del concepto, argumento trascendental, ideología, Lecourt

Abstract: The couple "philosophy of the concept" and "of the subject" distinguishes contemporary positions regarding philosophical fundamentation. The first understands the subject as an effect, and then implies a radical transformation of the philosophical task. As Lecourt has shown, Wittgenstein's Tractatus attacks the conception of philosophy as a discourse of fundamentation, assuming that this discourse produces first a break (between thought and being) and then tries to fit it through a discourse that guarantees the contact between the two fields previously instituted by the break. Absence of doubts concerning the meaning of propositions sets the Tractatus in the path of a regressive reasoning that not result in a transcendental argument because of the thesis on the impossibility of meta-language. The Philosophical investigations realized that this attack was still captive of one philosophical object (meaning) and try to eliminate it showing how it destroys itself when it enters in touch with rough practice of language. The absence of doubts is not anymore a sign of a fundamental semantic "knowledge", but a constitutive element of the practice of the languagegames, functioning as a requirement imposed over individuals in order to obtain and keep their condition of speakers, a position which is close to the conception of ideology developed by Althusser. We conclude showing some limitations of Wittgenstein's thought the category of philosophy of the concept allows us recognize.

Keywords: Wittgenstein, philosophy of the concept, trascendental argument, ideology, Lecourt

En este trabajo nos proponemos reflexionar sobre la filosofía de Wittgenstein a partir de un par de categorías elaboradas en el marco de la filosofía francesa, la oposición entre filosofía del concepto y filosofía del sentido o del sujeto, que a nuestro entender resultan superadoras respecto de la oposición entre filosofía analítica y continental, con la que usualmente se aborda la filosofía de Wittgenstein. La oposición entre "filosofía del concepto" y "fillosofía del sujeto o de la conciencia" fue propuesta por Jean Cavaillès ${ }^{2} \mathrm{y}$

${ }^{2}$ Cavaillès, Jean, Sur la logique et la théorie de la science, Paris, PUF, 1960; para una aproximación de Cavaillès a Wittgenstein, ver Lecourt, Dominique, El orden y los juegos. El positivismo lógico cuestionado, Buenos Aires, de la Flor, 1984, trad. J Ardiles Gray y Margarita Mizraji, pp. 241 y ss. Véase también el volumen colectivo de Cassou-Nougès, 
retomada luego por Foucault en ocasión de rendir homenaje a Canguilhem. ${ }^{3}$ Esta oposición se propone como una distinción transversal a aquella otra, más extendida, entre filosofía analítica y filosofía continental. El hecho de que la primera oposición esté dominada por una caracterización propiamente filosófica parece hablar, prima facie, en favor de la misma, en contraste con la oposición entre "analíticos" y "continentales", que, aunque es útil, resulta un tanto rústica en virtud de la metáfora geográfica que la domina. ${ }^{4}$

Si nos detenemos por un momento en la formulación de Cavaillès, quedan pocas dudas respecto de su pertinencia respecto de la filosofía de Wittgenstein. En efecto, Cavaillès encontraba el rasgo distintivo de la filosofía del concepto en un problema de fundamentación propio de la fenomenología husserliana, en la tensión entre formalismo e intuicionismo. Cavaillès cuestionaba el recurso de la fenomenología a lo trascendental, o a lo absoluto como un recurso para la fundamentación de lo verdadero en un poder subjetivo de unificación. La dificultad que señalaba Cavaillès consiste en que este poder subjetivo al que apela la fenomenología es insuficiente para explicar el desarrollo conceptual que caracteriza a los sistemas lógicos y científicos. No hay, de acuerdo con este pensador, ninguna manera de fundamentar las leyes lógicas en una conciencia trascendental. En efecto, una conciencia semejante tendría que tener sus normas, pero entonces "se precisaría una nueva investigación trascendental para vincular sus normas a una subjetividad superior, puesto que ningún contenido sino sólo la conciencia tiene la autoridad de ponerse a sí misma.", en consecuencia, continúa Cavaillès: "Si la lógica transcendental funda realmente a la lógica, no hay lógica absoluta (es decir, que gobierne la actividad subjetiva absoluta). Si hay una lógica absoluta, entonces

Pierre y Gillot, Pascalle (eds.), Le concept, le sujet et la science. Cavailles, Canguilhem, Foucault, Paris, Vrin, 2011.

${ }^{3}$ Foucault, Michel, "La vida: la experiencia y la ciencia", en Giorgi, Gabriel y Rodríguez, Fermín (comps.), Ensayos sobre biopolítica. Excesos de vida, Buenos Aires, Paidós, 2009, trad. de F. Rodríguez.

${ }^{4}$ Sobre los distintos modos de conceptualizar esta diferencia, véase el interesante libro de Domingues, Ivan, O continente e a ilha. Duas vias da filosofia contemporânea, São Paulo, Loyola, 2009. 
ella no puede sacar su autoridad sino de sí misma, no es trascendental." 5 Cualquiera que haya frecuentado las reflexiones de Wittgenstein sobre el problema de las reglas no dejará de percibir que Cavaillès y el austríaco se adentran en un terreno semejante.

En los últimos años una serie de ejercicios de aproximación entre las filosofías de Wittgenstein y la de Foucault han desarrollado argumentos para colocar a Wittgenstein bajo la sombra de la categoría de la filosofía del concepto. ${ }^{6}$ Estos estudios arrojan algunas consideraciones interesantes acerca de los ejes en torno a los que debe girar una exploración semejante: la crítica del psicologismo; la posibilidad de revisar el "quietismo político" de Wittgenstein en virtud de la preocupación creciente en su trabajo sobre la cuestión de la anormalidad y la normalidad, observación cuyo relieve se destaca a la luz de la importancia que esta preocupación tiene en los trabajos de Foucault y Canguilhem; y la que tal vez sea la cuestión fundamental, concebir a la filosofía como una práctica. Más aún, estos trabajos postulan la hipótesis de la influencia efectiva de Wittgenstein en el desarrollo del pensamiento de Foucault. La amplia comunidad de preocupaciones y problemas, así como los trabajos ya realizados en ese sentido, han despejado el terreno para realizar una confrontación y una crítica recíproca.

Dado este estado de cosas, llama poderosamente la atención, sin embargo, la ausencia de examen de las tesis althusserianas, ya que las coordenadas trazadas para la exploración recíproca de Foucault y Wittgenstein valen también para un abordaje con propósitos semejantes de Althusser y Wittgenstein. No se trata meramente de una vocación enciclopédica, sino de

${ }^{5}$ Cavaillès, op. cit., p. 65. Ver Montag, Warren, Althusser and His Contemporaries, Durham, Duke University Press, 2013, pp. 39 y ss., y Ricoeur, Paul, "El lenguaje, la acción, el humanismo" en Ricoeur, Paul, Filosofía, Vol. 4 de Ricoeur, Paul (ed.), Corrientes de la investigación en las ciencias sociales, Madrid, Tecnos-UNESCO, 1982, pp. 459460.

${ }^{6}$ Ver Gillot, Pascale y Lorenzini, Danielle, Foucault / Wittgenstein. Subjectivité, politique, éthique, Paris, CNRS éditions, 2016, y Arnold I. Davidson y Frédéric Gros (eds.), Foucault, Wittgenstein: de possibles rencontres, Paris, Éditions Kimé, 2011. 
que esta ausencia tiene efectos precisos en la lectura de la obra del vienés. ${ }^{7}$ Ciertos efectos de la operación que borra en el pensamiento de Foucault su relación con el materialismo histórico en general y con el pensamiento de Althusser en particular, alcanzan así a la lectura de Wittgenstein. ${ }^{8}$

La conjunción entre la filosofía de Wittgenstein y la filosofía althusseriana ha sido objeto de algunos intentos de abordaje importantes, aunque poco transitados. Entre ellos, el más notorio es el trabajo de Dominique Lecourt. ${ }^{9}$ Se trata de un antecedente que se vio afectado por la reconfiguración de la coyuntura teórica, la radical transformación del campo problemático de la filosofía y las ciencias humanas en los años 80 y 90, que la hizo aparecer pronto como un tanto desfasada en relación a su entorno. Sin embargo, creemos que ha llegado el momento que hace posible una relectura y una recuperación de estos trabajos, con el propósito de llevarlos un poco más lejos. Había en el trabajo de Lecourt algunas ideas de gran interés. Por una parte, un argumento sostenido a favor del reconocimiento de un antihumanismo teórico en la filosofía de Wittgenstein, de un embate a la "problemática antropológica", que ha quedado relativamente invisibilizado en la recepción corriente del pensamiento wittgensteiniano, en ocasiones por una toma de posición explícita de los intérpretes en contra de este movimiento, y en otras ocasiones por la

7 Por ejemplo, la excepción parcial del trabajo de Pascalle Gillot, "Foucault/Wittgenstein: une 'subjectivité sans sujet'?", que aborda las posiciones de Althusser, encuentra en Foucault y en Wittgenstein la emergencia de un yo filosófico que se constituye como sujeto de la meditación filosófica "a partir de la disolución del sujeto 'del pensamiento y de la representación"' (en Gillot y Lorenzini, op. cit., p. 76). He elaborado los lineamientos de una lectura opuesta en algunos trabajos previos; véase, por ejemplo: "Materialismo, ideología y juegos de lenguaje" en Ideas y valores, Vol 51, N ${ }^{\circ} 150$, diciembre de 2012 y "La cuestión del sujeto en Althusser y Wittgenstein" en Estudios de filosofía práctica e historia de las ideas, Dic 2014, vol.16, No 2, pp.53-83.

${ }^{8}$ Véase Legrand, Stephane, "El marxismo olvidado de Foucault", en AA.VV., Marx y Foucault, Buenos Aires, Nueva visión, 2005; Montag, Warren, "El alma es la prisión del cuerpo', Althusser y Foucault, 1970-1975”, en Youkali, No 8, dic. 2009, y recientemente Demirovic, Alex, "Why Should We Read Althusser (Again)?" en Viewpoint Magazine, https:/ /viewpointmag.com/2016/07/18/why-should-we-read-althusser-again/

${ }^{9}$ Ver Lecourt, Dominique, El orden y los juegos, y Lecourt, D. La philosophie sans feinte, Paris, Hallier/Albin Michel, 1982, p. 28. 
afirmación del mismo en el lenguaje de otra tradición teórica. Por otra parte, Lecourt sugería una interesante lectura de los límites del pensamiento de Wittgenstein en las Investigaciones filosóficas y de la relación de estos límites con los desarrollos de Sobre la certeza.

\section{Wittgenstein y la filosofía en el Tractatus}

El Tractatus-logico philosophicus ${ }^{10}$ está tramado, como se sabe, por una preocupación ética. Sin embargo, como el propio Wittgenstein le confesó a su amigo Ludwig von Ficker, editor de la revista Der Brenner y representante emblemático de las preocupaciones de la "cultura vienesa", ${ }^{11}$ la ética debía quedar forzosamente fuera de su filosofía. El Tractatus, dice Wittgenstein en la carta a su amigo:

se compone de dos partes: de la que aquí aparece, y de todo aquello que no he escrito. Y precisamente esta segunda parte es la importante. Mi libro delimita por dentro lo ético, por así decirlo; y estoy convencido de que; estrictamente SÓLO puede delimitarse así. Creo, en efecto, que aquello sobre lo que muchos hoy parlotean lo he puesto yo en evidencia en mi libro, guardando silencio sobre ello. ${ }^{12}$

Esta declaración, como clave para clarificar el sentido del libro, nos introduce de inmediato en un círculo, ya que la misma debe, a su vez, comprenderse a partir del propio texto que busca clarificar. El Tractatus es el trazado del límite (de una línea de demarcación) entre lo que puede y lo que no puede pensarse por medio del reconocimiento de los límites de lo que puede decirse. El establecimiento de este límite muestra la posición de la ética,

${ }^{10}$ Wittgenstein, Ludwig, Tractatus-logico philosophicus, Barcelona, Altaya, 1997, trad. de Jacobo Muñoz e Isidoro Reguera. Citamos esta obra de acuerdo al procedimiento usual, indicando el número de proposición antecedido por la abreviatura TLP.

${ }^{11}$ Ver Janik, Allan y Toulmin, Stephen, La Viena de Wittgenstein, Madrid, Taurus, 1983, trad. de I. Gómez Liaño, p. 24.

${ }^{12}$ Citado en Isidoro Reguera y Jacobo Muñoz, “Introducción” a Wittgenstein, L. op. cit., p. ix. 
exhibiendo lo poco que ésta puede esperar, en sentido positivo, de la filosofía ("Soy, pues, de la opinión de haber resuelto, en lo esencial, los problemas...", dice Wittgenstein en el "Prólogo" a esta obra, y añade a continuación que el valor de este trabajo consiste "en haber mostrado lo poco que se ha hecho con haber resulto estos problemas"13). El valor del libro radicaría entonces en lo mucho que puede esperarse en la ética de la liberación de la tutela de la filosofía. El contraste entre la posición de Wittgenstein y la de las filosofías dominantes de su tiempo difícilmente podría ser más acentuado. Cabe señalar al respecto la angustiosa preocupación que, más o menos contemporáneamente, agobiaba a Husserl por la suerte de las normas morales mientras no se lograra establecer una fundamentación racional incuestionable de las mismas: la necesidad de la "filosofía como ciencia estricta" era vista como un asunto crucial para la civilización occidental. ${ }^{14}$ Ante la carencia de un fundamento, Husserl temía que el escepticismo y el relativismo barrieran con todo, de modo que, de manera preventiva, desarrollaba una filosofía de la intencionalidad que retomando la tesis feuerbachiana de la objetividad especular, según la cual el modo específico de la relación de un ser con un objeto exterior es constitutivo de la esencia de ese objeto, pretendía abrir la vía de una exploración científica para la filosofía concebida como saber sin supuestos.

¿De qué manera la liberación de la tutela de la filosofía puede constituir un efecto liberador para la ética? Para responder a esta cuestión es preciso concentrarnos en la estrategia de Wittgenstein en el Tractatus. En efecto, no se trata sólo de que la filosofía, el texto filosófico, el Tractatus mismo, delimite lo decible y lo indecible, sino de que al hacerlo pone a la propia filosofía en cuestión. Wittgenstein presenta, en el célebre aforismo 6.54, el anteúltimo del Tractatus, la situación de la filosofía mediante un símil:

Mis proposiciones esclarecen porque quien me entiende las reconoce como absurdas (unsinnig), cuando a través de ellas - sobre ellas- ha salido fuera de ellas (Tiene, por así decirlo, que arrojar la escalera después de haber subido por ella). Tiene que superar estas proposiciones; entonces ve correctamente el mundo. (TLP 6.54)

\footnotetext{
${ }_{13}^{13}$ Ibid., p. 13.

${ }^{14}$ Husserl, Edmundo, La filosofía como ciencia estricta, Nova, Buenos Aires, 1962, trad. de Elsa Tabernig.
} 
Esta última declaración nos introduce de lleno en un terreno de difícil exploración, que debe abordarse a partir de la estrategia general de la obra. En efecto, el aforismo reclama cierta eficacia para la filosofía, aunque reniegue de otorgarle a las proposiciones de la filosofía correcta, la del propio Tractatus, un estatus diferente del de las de otras filosofías: unas y otras serían absurdos. Pero las filosofías a las que Wittgenstein se enfrenta son absurdas porque buscan funcionar como un metadiscurso, como un metalenguaje; la suya propia es absurda porque debe acometer un metalenguaje, esto es, "cometer una filosofía", para mostrar que el metalenguaje, el lugar del fundamento, es radicalmente imposible. Si se nos permite un juego de palabras, mientras las filosofías que se constituyen como un metalenguaje pretenden ser un saber sin supuestos, sin presunciones, puesto que lo dicen todo, la filosofía del Tractatus se constituye como una denuncia de del supuesto saber sobre el que estas filosofías se asientan, esto es, de la presunción constitutiva de las mismas.

Esta peculiar posición filosófica del Tractatus ha repercutido en las complicaciones que los intérpretes del pensamiento de Wittgenstein han experimentado para caracterizar su pensamiento. Jürgen Habermas ha concretado esta dificultad en una idea deslumbrante: la de Wittgenstein sería "una filosofía trascendental no afirmativa". ${ }^{15}$ Una filosofía que, partiendo del factum del lenguaje (la bipolaridad de la proposición, la comprensión del sentido), explora sus condiciones de posibilidad, para descubrir, gracias a las condiciones que ayuda a esclarecer, que no está en condiciones de enunciar los resultados a los que arriba. Lo que la metáfora de la escalera nos muestra es que quien comprende la obra debe ver al Tractatus bajo la lógica del como si: las sentencias que componen el libro se presentan como si fueran unas proposiciones acerca de la relación entre el lenguaje y el mundo que sólo se comprenden cabalmente cuando se entiende que no son realmente proposiciones. La caracterización de Habermas es sin dudas muy sugerente, en efecto, el tránsito regresivo del dato a sus condiciones de posibilidad, aquello a lo que podríamos querer llamar razonamiento trascendental, ${ }^{16}$ captura

${ }_{15}$ Ver Habermas, Jürgen, La lógica de las ciencias sociales, Madrid, Tecnos, 1996, trad. de Manuel Jiménez Redondo, p. 207.

${ }^{16}$ Ver Taylor, Charles, "La validez de los argumentos trascendentales", en su Argumentos filosóficos, Barcelona, Paidós, 1997, trad. de F. Birulés Beltrán. 
correctamente algo de lo que encontramos en el Tractatus. Sin embargo, lo que este análisis regresivo descubre, la teoría figurativa de la proposición, descansa sobre una distinción entre "decir" y "mostrar" que hace imposible, e innecesario, cualquier metalenguaje, lo que, como mostraremos, impide caracterizar a la estrategia del libro como la de un argumento trascendental.

Veamos esto con un poco más de detalle. La proposición puede figurar la realidad porque comparte con ésta la forma lógica: figura y realidad figurada son ambas hechos en el espacio lógico, concebido como la sumatoria de todos los estados de cosas posibles. Al figurar la realidad, la proposición no puede sino ostentar su forma lógica, valiéndose de su carácter de hecho dotado de una estructura particular para expresar un sentido: "La proposición muestra su sentido. La proposición muestra cómo se comportan las cosas si es verdadera. $\mathrm{Y}$ dice que se comportan así." (TLP 4.022).

Ahora bien, si tomamos en serio la imposibilidad de un metalenguaje, tenemos que renunciar a caracterizar la filosofía del Tractatus como una filosofía trascendental. En efecto, el tramo regresivo es sólo una parte de un argumento trascendental, aquella que queda limitada a las cuestiones de hecho, a aquellos aspectos necesariamente involucrados en el factum o el dato del que se parte. Sin embargo, lo central de una filosofía trascendental se concentra en las cuestiones de derecho, aquellas que muestran que no estamos sólo fácticamente constreñidos por aquellos factores que sostienen el dato evidente del que partimos. Una filosofía trascendental busca mostrar que nos asiste el derecho en la seguridad con la que sostenemos el dato inicial. Por ejemplo, en La crítica de la razón pura de Kant no sólo tenemos la "deducción metafísica de las categorías", que nos da la lista de los conceptos del entendimiento de acuerdo a los modos en los que de hecho juzgamos, sino también, y fundamentalmente, la "deducción trascendental de las categorías". Esta última busca mostrar que nuestra compulsión a pensar en términos de las categorías de entendimiento, en términos de causas por ejemplo, no es sólo una cuestión de hecho, un impulso arbitrario, sino que las categorías son también la condición de posibilidad de los objetos, es decir, que, por ejemplo, los objetos necesariamente tienen causas. ${ }^{17}$ Lo que define a un argumento trascendental es la postulación de un idealismo trascendental, o de

${ }^{17}$ Ver Stroud, Barry, "Transcendental Arguments", en The Journal of Philosophy, vol. LXV, $\mathrm{N}^{\circ}$ 9, 1968. 
un análogo del mismo que hace que las condiciones de posibilidad de la experiencia sean simultáneamente las condiciones del objeto, lo que nos permite afirmar que tenemos derecho a creer aquello que estamos irremediablemente inclinados a creer. Esta tesis no es privativa del kantismo, sino que puede revestir formas variadas, para la fenomenología las condiciones de manifestación de los objetos son las condiciones de toda objetividad, por ello, que algo se nos presente como tal o cual es constitutivo de su ser tal o cual. ${ }^{18} \mathrm{El}$ programa del positivismo lógico, con su énfasis en la reducción lógica de todos los enunciados científicos a los enunciados protocolares, por un lado, y la reducción del sentido al sentido empíricamente verificable, por la otra, realiza un doble movimiento que, podríamos decir, acarrea la reducción del mundo al mundo de la experiencia, con lo que provee los elementos requeridos para ser reconstruido como un argumento trascendental. Sea como sea, lo crucial en un argumento trascendental es que el movimiento regresivo está complementado por un movimiento reconstructivo.

En conclusión, si en el Tractatus hay un movimiento regresivo, desde cierto factum expresado en el prólogo hacia sus condiciones, el elemento reconstructivo falta por completo en esta obra. Ahora bien, para comprender la posición filosófica de Wittgenstein, lo crucial es determinar la naturaleza de esta ausencia.

Pasemos entonces a examinar algunos movimientos de este texto. Las proposiciones iniciales de esta obra insisten en una tesis muy singular, que sostiene que: "El mundo es la totalidad de los hechos, no de las cosas" (TLP 1.1), tesis cuyas consecuencias son desplegadas en profundidad por medio de una reductio ad absurdum: si el mundo fuera una totalidad de cosas, como quería el atomismo clásico, entonces la posibilidad de la combinación de una cosa y otra, de un átomo y otro, sería un asunto contingente y no existiría la "forma del mundo" (ver TLP 2.022, 2.026), que es una "forma lógica" (TLP 2.18). ${ }^{19}$ Un segundo movimiento vincula la forma lógica del mundo (el espacio lógico),

\footnotetext{
18 Ricoeur, op. cit, p. 454.

${ }_{19}$ Este es un paso crucial en el libro; el lector interesado puede consultar Fogelin, Robert, Wittgenstein, Londres, Routledge, 1987, o los comentarios a la nueva traducción del Tractatus por Luis M. Valdés Villanueva (Madrid, Tecnos, 2003).
} 
la simplicidad de los objetos y la posibilidad de hacer figuras de los estados de cosas. Es lo que en la literatura se conoce como "el argumento de la necesidad de los simples" (TLP 2.0201-2.0212). ${ }^{20} \mathrm{El}$ argumento establece que sólo si los objetos que componen los estados de cosas son simples puede haber una forma lógica (si los objetos no fueran simples, el espacio lógico podría agrandarse o decrecer). Por ejemplo, para figurar un hecho con la proposición "El actual rey de Argentina es pelado", para determinar qué hecho figura esta proposición, condición para que la misma sea bipolar como toda proposición en regla, deberíamos conocer si actualmente Argentina es o no una monarquía. En términos generales, si no hubiera objetos simples, al hacer una figura de un hecho deberíamos saber de qué mundo hablamos. Es decir, la posibilidad de hacer una figura dependería de otra figura, y en tal caso no podríamos pergeñar una figura de ningún hecho sin que se nos plantee el problema de las garantías: para pergeñar una figura, verdadera o falsa, necesitaríamos establecer la verdad de otra figura, para saber en qué mundo estamos figurando, etc. El absurdo es evidente: tendríamos que proponer al lenguaje (la figura) como condición de posibilidad del lenguaje (de la figura). Pero lo que tal vez sea más grave es que de esa manera se introduciría una fractura entre el lenguaje y el mundo, y presumiblemente emergería una disciplina, la filosofía o la semántica, a la que le correspondería construir el puente.

Ahora bien, la ganancia que encuentra Wittgenstein al plantear el problema de lo pensable a través de lo que se puede decir es ostensible: mientras que intentar demarcar los límites de lo pensable nos lleva forzosamente a intentar pensar ambos lados del límite (lo pensable y lo impensable), lo cual, al tomar a ambos términos como objetos del pensamiento, plantea la cuestión del límite como una asunto de re, arrojándonos en los brazos de un argumento trascendental encargado de establecer la legitimidad de la distinción trazada entre la pensabilidad de lo pensable y la impensabilidad de lo impensable, es decir, de un argumento que nos tendría que proveer una garantía de la identidad del pensamiento y lo pensable. En cambio, el camino que pasa por los límites del lenguaje traza los límites de lo pensable desde el

\footnotetext{
${ }^{20}$ Ver, por ejemplo, Lock, Grahame, Wittgenstein. Philosophie, logique, thérapeutique, Paris, P.U.F, 1992 , p. 37.
} 
interior del lenguaje, como una cuestión de dicto, es decir, como una cuestión que obtura que nos salgamos de lo que puede decirse con sentido. Lo que queda del otro lado del límite de lo decible no será entonces "un sentido que es un sinsentido", ${ }^{21}$ sino una expresión lingüística, que es un hecho en el mundo como cualquier otro, pero que a pesar de ser un hecho (es una expresión lingüística) no posee sentido porque viola la legalidad inmanente del lenguaje, es decir, la forma lógica, legalidad que el propio lenguaje revela por sí mismo en su uso. Por ejemplo, como sostiene Hartnack: "Las proposiciones en las que se afirma que el lápiz es amable, inteligente o musical no son figuras, no son proposiciones; son, simplemente, sinsentidos". ${ }^{22}$

Con esto tenemos ya los elementos más importantes para caracterizar la posición de Wittgenstein, pero permítasenos dar un rodeo por la teoría figurativa, para poder establecer estas conclusiones de manera más convincente.

Dominique Lecourt ha llamado la atención sobre la importancia de Herzt y Boltzmann en el Tractatus. De hecho, Hertz es uno de los pocos nombres propios que aparecen en esta obra. En el aforismo 4.04 Wittgenstein dice: "En la proposición tienen que poder distinguirse exactamente lo mismo que en el estado de cosas que representa. Ambos deben poseer igual multiplicidad lógica (matemática). (Cfr. la mecánica de Hertz sobre modelos dinámicos.)". La siguiente reflexión de Boltzmann, seguidor de Hertz y con quien Wittgenstein quiso estudiar física según el relato de von Wright, ${ }^{23}$ proyecto que no pudo realizarse debido al suicidio del físico en 1906, nos da una idea cabal de la procedencia de la teoría figurativa de la proposición. En efecto, en el artículo "Model" escrito en 1902 para la Enciclopedia Británica, Boltzmann sostiene:

\footnotetext{
${ }^{21}$ En términos de las Investigaciones filosóficas, Altaya, Barcelona, 1999, trad. de Ulises Moulines y Alfonso García Suárez, lo que hay que comprender es, ante todo, que cuando se dice que una expresión carece de sentido "no es como si su sentido careciera de sentido" (IF \# 500).

${ }^{22}$ Hartnack, Justus, Wittgenstein y la filosofía contemporánea, Ariel, Barcelona, 1972, trad. J. Muñoz, p. 56.

${ }^{23}$ Von Wright, Georg Henrik, "Esquema biográfico" en AA. VV., Las filosofias de Wittgenstein, Barcelona, Oikos-Tau, 1966, trad. de Ricardo Jordana, pp. 24-25.
} 
Los modelos son de la mayor importancia en las ciencias matemáticas, físicas, y mecánicas. Desde hace mucho tiempo la filosofía ha reparado en que la esencia de nuestro proceso de pensamiento reside en el hecho de que atribuimos a los objetos reales que tenemos alrededor atributos físicos particulares -nuestros conceptos- y que por medio de ellos intentamos representar los objetos en nuestra mente. Tales puntos de vista en otros tiempos fueron considerados por los matemáticos y los físicos como nada más que vanas especulaciones, pero en un período más reciente, se los puso en relación más estrecha con el cuerpo íntegro de la teoría matemática y física: según esta perspectiva nuestros pensamientos mantienen con las cosas la misma relación que los modelos con los objetos que representan. La esencia de ese proceso consiste en atribuir a cada cosa un concepto que tenga un contenido definido, pero sin que eso implique que haya una completa similitud entre la cosa y el pensamiento; porque, naturalmente, no sabemos mucho acerca del parecido de nuestros pensamientos con las cosas a las cuales los vinculamos. El parecido que hay reside principalmente en la naturaleza de la conexión, y la correlación es análoga a la que se establece entre el pensamiento y el lenguaje, el lenguaje y la escritura, las notas sobre la partitura y los sonidos musicales, etc. Aquí, por supuesto, la simbolización de las cosas es el punto importante, aunque, cuando eso es posible, se busque la más perfecta correspondencia entre ambos: por ejemplo, la gama se imita poniendo las notas sobre el pentagrama más arriba o más abajo. ${ }^{24}$

En esta cita nos topamos con la solución que Boltzmann creyó encontrar al problema de los modelos en mecánica: los mismos significan en virtud de su isomorfismo con la realidad significada, permitiendo "al ojo desnudo" reconocer la estructura, junto con la manifestación de cierta cautela escéptica acerca de la relación de representación entre los conceptos utilizados y la realidad significada. Se trata, como el desarrollo de Wittgenstein en el Tractatus nos permite apreciarlo, de un enunciado que está a caballo entre dos problemáticas diferentes. Por un lado, una problemática tradicional, que encara la significatividad como una dimensión que podríamos denominar vertical, ya que parte de la mente, atraviesa el signo y acaba en el mundo, en la referencia. Por otra parte, tenemos una problemática que hace descansar la significatividad en una dimensión horizontal, es decir, en la conexión entre los signos.

${ }^{24}$ Boltzmann, citado en Lecourt, Dominique, El orden y los juegos, pp. 181-182. 
Como lo ha demostrado Lecourt, esta referencia a los modelos mecánicos tiene una importancia crucial, largamente desatendida, en el Tractatus. Los trabajos de Russell y Frege, en donde se pone usualmente el acento al interpretar el Tractatus, tuvieron para Wittgenstein el atractivo irresistible de permitirle generalizar la concepción de los modelos mecánicos que le ofrecían Hertz y Boltzmann, despejando la posibilidad, por medio de la distinción entre gramática superficial y gramática profunda, de aplicarla a todo lo ancho y lo largo del lenguaje, incluyendo el lenguaje ordinario. Por medio de Russell y Frege, Wittgenstein pudo desembarazarse de los resquemores escépticos que dominaban la obra de Fritz Mauthner, para quien la "crítica del lenguaje" era comprendida como una liberación de las ilusiones, orientada a mostrar que el hombre no podrá jamás trascender una descripción metafórica (bildliche Darstellung) del mundo, ni por medio del lenguaje cotidiano ni por medio del lenguaje filosófico. ${ }^{25}$ Cuando Wittgenstein sostiene que "Toda filosofía es 'crítica lingüística"', (4.0031), añade inmediatamente la restricción, "En todo caso, no en el sentido de Mauthner". Seguimos aquí una vez más a Lecourt: “¿Cuál es la raíz teórica del 'escepticismo epistemológico' radical de Mauthner que Wittgenstein combate en nombre de Hertz y Boltzmann? ¿Cuál, sino haber presupuesto, en la línea de Schopenhauer, que forma lógica aparente y forma real eran idénticas?" 26 Cuestionar este presupuesto es, de acuerdo a Wittgenstein, "el mérito de Russell" al haber mostrado que la forma aparente y forma lógica del lenguaje no coinciden necesariamente (en nuestro ejemplo, que la descripción definida "el rey de la Argentina" no es una expresión nominal, sino una proposición existencial que posee una complejidad lógica que se puede explicitar rigurosamente). En otros términos, por medio de los trabajos de Russell y Frege, Wittgenstein pudo generalizar las conclusiones de Hertz y Boltzmann sobre la función de los modelos en mecánica, eludiendo, por un lado, los resquemores escépticos de los científicos y eludiendo, por el otro, el planteo del problema de las garantías (o la carencia de garantías) de los filósofos. Todo el Tractatus, en efecto, contradice el escepticismo epistemológico que se deriva de la posición de Mauthner. Pero esta contradicción no es la del dogmático, que acepta el problema escéptico y lo responde en sus propios términos, muy por el contrario, la misma depende del

${ }^{25}$ Ver Lecourt, El orden y los juegos, p. 178 ; ver Janik y Toulmin, op. cit., pp. 151 y ss.

${ }^{26}$ Lecourt, El orden y los juegos, p. 181. 
rechazo de la pregunta mauthneriana, implicado en el rechazo radical del metalenguaje.

Desde esta perspectiva, el hecho de que Wittgenstein nunca haya cedido a la tentación de dar ejemplos de objetos simples es de un rigor impecable. En efecto, la simplicidad de los elementos, su individualidad, depende por completo de la forma lógica, de la estructura del lenguaje, la simplicidad de los elementos es algo que nos viene indicado por su posición en la estructura de la proposición. Es cierto que Wittgenstein distingue entre la relación figurativa (la correlación biunívoca entre los elementos de la figura (nombres) y los elementos del hecho figurado (objetos) (ver TLP 2.1514) y la forma de la figuración, que es la forma de realidad que comparten la figura y lo figurado, "la posibilidad de que las cosas se interrelacionen al igual que los elementos de la figura" (TLP 2.151, ver 2.15 y 2.17), y en última instancia, toda figura es una forma lógica porque como mínimo comparte con lo figurado la circunstancia de ser hechos en el espacio lógico, y por tanto comparten la forma de figuración lógica. La relación figurativa parece depender de alguien que establezca la correlación, pero esta dependencia es un efecto de superficie: por una parte, al no ser los objetos entes subsistentes (el mundo es la totalidad de los hechos, no de las cosas, como dijimos), sino formas cuya naturaleza consiste en la relación interna que guardan con sus posibilidades de combinación con otros objetos para formar "hechos atómicos" o "estados de cosas" (Sachverbalten), la contingencia de la relación figurativa no puede alterar la necesidad de la forma lógica. Por otra parte, el concepto de la relación figurativa da cuenta de una distinción analítica y no de un momento fundacional: un nombre sólo tiene significado (Bedeutung) en el contexto de una proposición (un elemento de una figura sólo tiene significado en el contexto de una figura) y la relación de un nombre con un objeto sólo es accesible a través del uso de la proposición, accedemos al mismo a través de elucidaciones (Erläuterungen) (ver TLP 3.263).

Como si esto fuera poco, Wittgenstein se ocupa de explicitar las consecuencias de su concepción del lenguaje en relación al sujeto, insistiendo en que el yo no es un hecho en el mundo, lo que excluye de plano al sujeto psicológico ("Esto muestra también que el alma -el sujeto, etc.-, tal como es concebida en la actual psicología superficial, es una quimera. Un alma compuesta no sería ya, ciertamente, un alma." TLP 5.5421). Pero también, si atendemos a la caracterización que hace Paul Ricoeur del sujeto trascendental: 
"si el juicio y no el concepto es la última instancia a la que reenvía la fundación trascendental de la lógica, el juicio es siempre el juicio de alguien y la subjetividad no podría ser anónima", ${ }^{27}$ comprenderemos que excluye también al sujeto trascendental. La posición trascendental, que muchos intérpretes creyeron encontrar en el Tractatus, sostendría que, sin un sujeto trascendental o un sujeto metafísico, no habría proposiciones acerca del mundo. En lo que sigue intentaremos mostrar que las funciones sintéticas del sujeto trascendental son excluidas por razones sistemáticas en la teoría pictórica de la proposición. El orden de la fundamentación trascendental insiste en que, a menos que haya un sujeto del juicio, no habría experiencia posible ni, por tanto, pensamiento coherente, es invertido radicalmente por Wittgenstein.

Wittgenstein ilustra este problema a través de una analogía con el campo visual: “¿Dónde descubrir en el mundo un sujeto metafísico? Dices que ocurre aquí enteramente como con el ojo y el campo visual. Pero el ojo no lo ves realmente. Y nada en el campo visual permite inferir que es visto por un ojo." (TLP 5.633). El problema que nos aqueja ha sido apresado magistralmente en unos versos de Antonio Machado: "el ojo que ves no es / ojo porque tú lo veas / es ojo porque te ve", ${ }^{28}$ si pensamos en la situación en la que vemos nuestro rostro frente a un espejo. La analogía de Wittgenstein captura bien la dificultad irresoluble que implica toda posición trascendental (la primacía del juicio, que hace de la experiencia, como indica Ricoeur, la experiencia de alguien). En efecto, lo que el ejemplo del campo visual exhibe es que la genuina dificultad no es la que supone el solipsista o el filósofo trascendental, esto es, que lo único que existe con certeza sean los contenidos de mi mente y que el problema consista en concebir cómo es posible que otros tengan lo que yo mismo tengo: mi campo visual, mis experiencias. Al contrario, insiste Wittgenstein, nada en el campo visual indica que es visto por un ojo, es decir, nada dentro del campo visual indica que es mío. La dificultad real no es, en consecuencia, saber cómo es posible que otros tengan lo que yo tengo, sino comprender de dónde, cómo y porqué surge y se impone con tanta fuerza y naturalidad la idea de un yo en el

\footnotetext{
${ }^{27}$ Ricoeur, Paul, op. cit., p. 456.

${ }^{28}$ Machado, Antonio, Poesía y prosa. Antología, Colihue, Buenos Aires, 1991, selección, introducción y propuestas de trabajo de Cristina Sisca de Viale, p. 95, Otro ejemplo semejante del propio Machado es: "los ojos porque suspiras / sábelo bien / los ojos en que te miras / son ojos porque te ven", p. 96.
} 
que inhiere la experiencia. Ateniéndonos estrictamente a la experiencia, lo más que podemos decir es que "se ve" o que "hay" tal o cual cosa en el campo visual. La restricción de Wittgenstein ("nada en el campo visual permite inferir que es visto por un ojo.") nos da una pista de que debemos buscar la solución a este enredo fuera del campo visual o de la experiencia. Como lo expresa Wittgenstein un poco después "El yo entra en la filosofía por el hecho de que 'el mundo es mi mundo"' (TLP 5.641, destaque nuestro). Es importante que nos detengamos en este hecho. Se trata, ni más ni menos, que del hecho de que "se piensa", de que se formulan proposiciones, figuras de los hechos que se articulan según las diferentes posiciones, o "puntos de vista" desde las que se enuncian las proposiciones. Esta circunstancia, es decir este hecho, produce como efecto lo que llamamos "yo".

En su período intermedio Wittgenstein extrajo con más claridad las consecuencias de esta posición a propósito de los enunciados acerca de estados sensoriales. En Observaciones filosóficas \# 57 Wittgenstein se preguntaba qué ocurriría si intentáramos representar la vivencia inmediata sin el recurso a un pronombre personal, para lo cual responde en \# 58:

...si yo L. W., tengo un dolor de muelas, se dice: 'hay dolor de muelas'. En otros casos: 'A se comporta como L. W. lo hace cuando hay dolor de muelas'. El lenguaje puede tener a cualquiera como centro. El que me tenga a mí como centro radica en su aplicación. Esta posición especial no puede expresarse. Que yo diga que eso representado no es una cosa más entre otras, o que diga que no puedo expresar la ventaja de mi lenguaje -ambos casos conducen a lo mismo." 29

Se aprecia aquí con claridad que la posición del sujeto, o del yo, no es la posición de un sujeto trascendental, ya que el sujeto o el yo en cuestión adviene a su peculiar modo de existencia en virtud del lenguaje, su centralidad no es una condición sino un efecto (necesario) del uso del lenguaje.

Podemos pasar ahora a considerar el párrafo en el que han hecho pie diversas interpretaciones del Tractatus como una filosofía trascendental: "El yo entra en la filosofía por el hecho de que el 'mundo es mi mundo'. El yo

${ }^{29}$ Wittgenstein, Ludwig, Observaciones filosóficas, UNAM, México, 1997, trad. de A. Tomasini Bassols. 
filosófico no es el hombre, ni el cuerpo humano, ni el alma humana, de la que trata la psicología, sino el sujeto metafísico, el límite -no una parte del mundo." (5.641) Las observaciones precedentes socavan la posibilidad de leer aquí la afirmación de un sujeto trascendental con funciones sintéticas. Por el contrario, el yo, el "sujeto metafísico", depende de la gramática lógica, esto es, se muestra en el uso de la proposición, en virtud del becho de que hay lenguaje representativo.

Para concluir con nuestro abordaje del Tractatus, resumamos lo central de nuestra interpretación: rechazamos una lectura trascendental de esta obra, fundamentalmente en virtud de que el segundo movimiento de un argumento trascendental, el movimiento reconstructivo que le otorga estatuto de derecho a una pretensión de hecho, está por completo ausente en el pensamiento de Wittgenstein, no por una omisión contingente, por un descuido, sino por poderosas razones sistemáticas. ${ }^{30} \mathrm{El}$ problema del conocimiento queda enterrado en su solución, esto es, en la elucidación de la relación figurativa, de manera tal que la filosofía ya no puede legislar sobre el mismo: no hay figuras que sean verdaderas a priori y el establecimiento de la verdad de una figura rebasa las competencias de la filosofía.

En cuanto a la estrategia del Tractatus lo menos que podemos decir es que la misma es peculiar, la facticidad del lenguaje, la bipolaridad de la proposición que en el "Prólogo" aparece como un dato, no es abordada, como dijimos, por medio de un argumento trascendental que sublime esta factualidad, esta "pretensión de hecho", en una garantía, legitimando a priori el derecho de la misma. Al contrario, la facticidad del lenguaje es destacada por medio de un argumento que establece la imposibilidad de todo metalenguaje, es decir, a fortiori, de toda garantía de la relación del lenguaje con el mundo. Luego de este rodeo, que despeja el asedio de la exigencia de garantías filosóficas, el estatuto de la pretensión cambia, ya que no se la puede seguir

${ }^{30}$ Corrijo aquí la lectura del Tractatus que hice en mi trabajo "La cuestión del límite y el Tractatus como una reflexión trascendental" (Discusiones filosóficas, vol. 9, $\mathrm{N}^{\circ} 13$, jul.-dic. 2008, pp. 13-23), donde me dejé llevar por la presencia de un dato incuestionable y un movimiento regresivo para señalar la presencia de un argumento trascendental en el Tractatus. Obvié el hecho de que un razonamiento regresivo sin su complemento reconstructivo no es más que una descripción. 
viendo como una pretensión de hecho (lo que significa algo así como: arbitraria hasta que se demuestre lo contrario), pero tampoco podemos verla como una pretensión justificada, por ello creemos que lo más adecuado es decir que al final del camino (luego de subir por la escalera) no ya podemos verla como una pretensión. Este es el punto que algunos intérpretes señalaron como el spinozismo del Tractatus, ${ }^{31}$ en el cual todo lo que podemos decir es: hay lenguaje representativo, de la misma manera en que Spinoza sostenía: "babemus enim ideam veram".

Si a partir de lo dicho queremos ahora caracterizar la concepción de la filosofía de Wittgenstein, nos encontramos ante una situación difícil. La filosofía tiene evidentemente efectos: ayuda a despejar ciertos malentendidos y enredos y así puede ayudar a plantear de manera adecuada los problemas, a ver el mundo correctamente, lo que tiene importantes consecuencias en el terreno de la ética. ${ }^{32}$

\section{Wittgenstein y la filosofía en las Investigaciones filosóficas}

Pasemos ahora a las Investigaciones filosóficas. ${ }^{33}$ Este texto, con el indudable desmontaje del andamiaje del Tractatus que ofrece, nos plantea un problema acerca de si esta discontinuidad se verifica también respecto a la estrategia filosófica fundamental que acabamos de describir. En efecto, más allá de ciertas discontinuidades, algunas de las cuales analizaremos, en las Investigaciones Wittgenstein vuelve a plantear una batalla contra el discurso filosófico concebido al modo tradicional tanto como lo hacía en el Tractatus. La meta de evitar la posibilidad del discurso filosófico concebido como un discurso de

31 Ver Lock, op. cit., p. 54-58, Lecourt, El orden y los juegos, p. 181, y Granger, GillesGaston, Wittgenstein, Paris, Seghers, 1969; más recientemente, Suchting, Wal, "Althusser's Late Thinking on Materialism", en Historical Materialism, vol. 12, $\mathrm{N}^{\circ} 1$, 2004 y Baltas, Aristides, Peeling Potatoes or Grinding Lenses. Spinoza and Young Wittgenstein Converse on Immanence and its Logic, Pittsburg, University of Pittsburg Press, 2012.

32 Remito aquí a Lock, op. cit., pp. 55 y ss.

33 Wittgenstein, Ludwig, Investigaciones filosóficas. También aquí usamos la convención usual y nos referimos a esta obra seguida del número de parágrafo, cuando las observaciones no estén numeradas con parágrafos, referiremos el número de página al pie del texto. 
legitimación y fundamentación permanece, aunque la táctica ha cambiado sensiblemente. ¿Implica esto un cambio de estrategia?

En el "Prólogo" a las Investigaciones encontramos un conjunto de observaciones preciosas respecto de este problema. En efecto, Wittgenstein reflexiona allí sobre la factura de esta obra, en la cual trabajó durante más de quince años, sobre la pluralidad de temas que aborda (el concepto de significado, de proposición, de lógica, los fundamentos de la matemática, los estados de conciencia, etc.), y sobre todo, acerca de la modalidad que ha tomado el resultado: el de un conjunto de "anotaciones" de sus pensamientos esparcidas en párrafos breves, que algunas veces se desarrollan en largas secuencias sobre el mismo tema, y que en otras saltan más o menos abruptamente de un dominio a otro. Wittgenstein nos confiesa su intención frustrada de reunir todo ese material en un libro en el cual los pensamientos progresaran de un tema a otro "en una secuencia natural y sin fisuras" y reflexiona sobre los motivos que lo llevaron a rehusar intentar ensamblar sus "resultados en una totalidad semejante". ${ }^{34} \mathrm{El}$ motivo inmediato de esta renuncia, nos confiesa el filósofo, es que sus pensamientos "desfallecían tan pronto como los obligaba a proseguir, contra su inclinación natural, en una sola dirección". Pero no todo es pérdida, ya que pronto se le ofrece al lector una preciosa indicación sobre estas "anotaciones filosóficas", al reconocer que su fracaso está motivado por la naturaleza misma de la investigación, que "nos obliga a atravesar en zigzag un amplio dominio de pensamiento en todas las direcciones. Las anotaciones filosóficas de este libro son como un conjunto de bosquejos de paisajes que han resultado de estos largos y enmarañados viajes.” Y lo que tal vez es lo más importante de todo, Wittgenstein reconoce que los mismos puntos "fueron continuamente tocados de nuevo desde diferentes direcciones y siempre se esbozaron nuevos cuadros", para concluir que "este libro es en realidad un álbum". Poco después Wittgenstein ofrece otra indicación crucial: que sus nuevos pensamientos "sólo podían recibir su correcta iluminación con el trasfondo y el contraste" 35 de su anterior modo de pensar, cristalizado en el Tractatus.

Detengámonos un momento a reflexionar sobre lo que estas observaciones implican en cuanto a la estrategia del libro. Por un lado,

\footnotetext{
34 Ibid, p. 11.
}

35 Id. 
encontramos una renuncia explícita a presentar un discurso filosófico sistemático, lo cual, si proseguimos la metáfora del paisaje que domina el prólogo, significaría que se rehusó a elaborar un mapa del mismo, escogiendo en su lugar ofrecer bosquejos de lo que se muestra al paseante. Tenemos aquí una indicación importante acerca de la orientación que tomará la investigación. Si nos apresuráramos un poco a tomar otra de las metáforas reveladoras del libro (ver IF \# 18), tendríamos que decir que las anotaciones filosóficas en cuestión confrontan el conocimiento que posee un habitante de la ciudad en la que reside, o que el baqueano puede poseer del territorio que recorre, con el mapa o el plano que un geógrafo puede realizar de los mismos. Esta metáfora podría proseguirse, insistiendo en la arbitrariedad de los límites, que los mapas presentan con toda naturalidad como un asunto espacial, como un elemento de la realidad representada, al mismo nivel que otros elementos geográficos como las montañas y los ríos, podríamos insistir en la antecedencia de la orientación práctica en un territorio sobre la representación del mismo en un mapa, etc. Se trata, sin dudas, de orientaciones valiosas, sin embargo, creemos que, para comprender mejor el contraste de las Investigaciones con el Tractatus, es decir, la especificidad de las Investigaciones, tendremos que preguntarnos algo más acerca de cuáles son las dificultades que Wittgenstein señala que radican en la propia naturaleza de la investigación.

Ya hemos comentado con cierta extensión la estrategia del Tractatus. Dicho con pocas palabras, en el Tractatus el cierre de la vía del fundamento, la exclusión del metalenguaje, se realiza a través de algunos de los recursos favoritos del discurso filosófico, se realiza more logico, de manera análoga a como la filosofía spinoziana se desarrollaba more geometrico. En el Tractatus, la estrategia de Wittgenstein es la de una elucidación inmanente, con lo cual el problema central del libro, el de la relación del lenguaje con el mundo, o de la proposición con el hecho, queda hundido en su solución. Ello desencadena un efecto liberador, ya que elude la formulación de un discurso filosófico, protegiendo así a otros ámbitos (ética, estética) de su colonización por la filosofía. En resumidas cuentas, Wittgenstein esperaba que el silencio que desencadena la elucidación inmanente funcionara como una neutralización anticipada de este intento de colonización. Para ello, el silencio filosófico debía estar soldado a la forma lógica del lenguaje. 
Esta estrategia hizo agua de distintas maneras. Por una parte, el estatus ambiguo de la posición filosófica del Tractatus permitió distintas apropiaciones filosóficas, su reinscripción en el marco de la "filosofía crítica" al estilo kantiano, ${ }^{36} \mathrm{o}$ la colonización de la posición filosófica de Wittgenstein por estrategias como la del positivismo lógico, que se abalanzaron sobre el silencio del Tractatus para llenarlo de palabras, desentendiéndose de que eso implicaba una modificación esencial de su posición filosófica. Por lo demás, el propio Wittgenstein encontró dificultades en relación con la independencia lógica de las proposiciones sobre los colores, lo que lo llevó poco a poco a desconfiar que hubiera una forma lógica. ${ }^{37}$

Dicho en otros términos, el Tractatus parece haberse equivocado en su diagnóstico, en su comprensión del dispositivo filosófico tradicional, al haber creído que lo central del mismo consistía en producir una herida, una separación entre las palabras y las cosas (o en términos tradicionales, entre el pensamiento y el ser), para cicatrizar luego esa herida por medio de un discurso que garantice el contacto entre los dos dominios instaurados por la herida inicial, para pasar luego a asegurar esa cesura, instaurándose como discurso amo. Dicho en términos más sencillos, el Tractatus es una denuncia del discurso filosófico, un intento por neutralizarlo que aprehende efectivamente un rasgo del dispositivo filosófico, pero que, según veremos, dejó en las sombras otros rasgos, todavía más importantes que aquellos. Para peor, el hallazgo de algunas dificultades en la forma lógica, vinculadas a las proposiciones sobre los colores, amenazaba con reabrir la herida, la separación, en el interior de un discurso que se asentaba precisamente sobre la denuncia de esta separación.

No sorprende, entonces, que las Investigaciones filosóficas comiencen por un desmontaje de las ideas centrales del Tractatus. En efecto, la obra se abre con un comentario de una cita de Agustín de Hipona donde éste recuerda su aprendizaje del lenguaje. Agustín describe su recuerdo en términos coloquiales

\footnotetext{
36 Ver Stenius, Erik, Wittgenstein's Tractatus: A Critical Exposition of its Main Lines of Thought, Ithaca, Cornell University Press, 1960, y Pears, David, Wittgenstein, Barcelona, Grijalbo, 1973, trad. de José Panells.

37 Ver Waismann, Friedrich, Ludwig Wittgenstein y el círculo de Viena, México, FCE, 1973 y Cabanchik, Samuel, Wittgenstein. Una introducción, Buenos Aires, Quadrata, 2010, p. 46 y ss.
} 
acerca de cómo, siendo un infante, aprendió su lengua materna coligiendo lo que los mayores querían decir con una u otra expresión, aprehendiendo los significados, las cosas a las que hacían referencia las palabras de los mayores, para posteriormente, una vez que se hubo acostumbrado a pronunciar él mismo las palabras, encontrarse en condiciones de dar expresión a las afecciones de su alma. Wittgenstein comenta este fragmento señalando que en el mismo se expone: "una determinada figura de la esencia del lenguaje humano. Concretamente ésta: Las palabras del lenguaje nombran objetos -las oraciones son combinaciones de esas denominaciones." (IF\# 1). El término figura (Bild, picture) es usado aquí en un sentido distinto al del Tractatus. Significa ahora una imagen conceptual rústica, susceptible de múltiples refinamientos, algo así como un paradigma en el sentido kuhniano, que provee un conjunto de aplicaciones ejemplares ("Quien así describe el aprendizaje del lenguaje piensa, creo yo, primariamente en sustantivos como 'mesa', 'silla', 'pan' y en nombres de personas" IF \# 1), y que deja abierto un conjunto de puzzles ("y sólo en segundo plano [piensa] en los nombres de ciertas acciones y propiedades, y piensa en los restantes géneros de palabras como algo que ya se acomodará").

Es importante detenernos en algunas cuestiones que suscita la apertura del libro. El concepto de figura ilustra la pretensión del discurso filosófico de tener un objeto bien establecido, en el caso que examinamos, el significado, objeto que irradia su influencia hacia un conjunto de problemas que están irresueltos, pero que se presume que podrían resolverse con sus recursos. ${ }^{38} \mathrm{Lo}$ que está en cuestión en el concepto de figura son entonces las características definitorias del discurso filosófico, un discurso que pretende poseer objetos definidos cuyo ámbito de incumbencia es universal. En este sentido, la apertura de Investigaciones destaca el compromiso del Tractatus con uno de esos objetos filosóficos pretendidamente bien establecidos: el concepto de significado.

El dato de la ausencia de dudas en relación con el sentido arrojó al Tractatus en la senda de un razonamiento regresivo. La estrategia de las

\footnotetext{
${ }^{38}$ Por otra parte, esta figura parece tener efectos más allá del discurso filosófico, ya que, si bien las memorias de Agustín son unas reflexiones de filósofo, lo son más en el sentido de un genitivo objetivo que subjetivo, es decir, no son reflexiones estrictamente filosóficas, como no son comidas filosóficas las comidas que prepara un filósofo.
} 
Investigaciones en este punto será muy distinta. Wittgenstein cierra el paso de manera anticipada a este movimiento; así dirá: "No digas: 'Tiene que haber algo común a ellos o no los llamaríamos <juegos >' -sino mira si hay algo común a todos ellos (...) ¡no pienses, sino mira!” (IF \# 66). Esta observación no es una apelación a la irreflexividad, al dogmatismo o al empirismo, sino parte de una estrategia que busca mostrar que los objetos filosóficos aparentemente mejor establecidos se destruyen tan pronto como los ponemos en contacto con el terreno áspero de la práctica efectiva del lenguaje.

Así, el paso siguiente del examen de la concepción agustiniana consiste en analizar su validez a propósito de lo que parecen ser sus aplicaciones más favorables: la nominación de objetos como mesa, silla, pan y nombres de personas. La crítica de las explicaciones ostensivas de las palabras pronto muestra que esta figura no vale ni siquiera para sus aplicaciones ejemplares: "la definición ostensiva puede en todo caso ser interpretada de maneras diferentes" (IF \# 28), el aprendizaje de la lengua materna no se realiza por medio de una explicación o una inferencia: "El niño emplea esas formas primitivas de lenguaje cuando aprende a hablar. El aprendizaje del lenguaje no es aquí una explicación, sino un adiestramiento." (IF \# 5).

Poco a poco Wittgenstein desgrana de la crítica de este primer objeto filosófico un conjunto de nociones que apuntan a una concepción diferente, el significado remite al uso ('Y cómo 'interpreta' él la definición se muestra en el uso que hace de la palabra explicada" IF \# 29), el lenguaje es una forma de actividad (“... imaginar un lenguaje es imaginar una forma de vida" IF \# 19). Poco después caen bajo la mirada crítica de Wittgenstein los demás pilares del Tractatus: el concepto de análisis y de lo simple, el de la determinación del sentido, el de orden del lenguaje, la necesidad metafísica elucidada como necesidad gramatical. Hay un rasgo de este análisis que lo hace peculiar y es que aun cuando el mismo es fuertemente concluyente, por ejemplo, en la crítica de las definiciones ostensivas se muestra que un acto interno de "dirigir la atención" no es constitutivo de la comprensión, ya que no es ni necesario (IF \# 33) ni suficiente (IF \# 34), Wittgenstein sin embargo no establece una conclusión positiva acerca de la naturaleza de la comprensión. Es indudable que cada paso de la argumentación desgrana algunas observaciones positivas, pero, como veremos, es importante estar alerta respecto de su estatuto. 
Ateniéndonos ahora estrictamente al desarrollo de estas "anotaciones", lo que se destaca es que las observaciones positivas de Wittgenstein no poseen el mismo estatuto que las proposiciones filosóficas. Incluso la estructura retórica del texto está armada en torno a una dualidad de voces, una, que aparece usualmente entre comillas, se apropia de las observaciones que va desgranando la confrontación de los objetos filosóficos con la aspereza de los juegos de lenguaje en términos de lo que podríamos denominar un desfasaje de problemáticas. ${ }^{39}$ Esto es, allí donde, por ejemplo, las observaciones muestran que la práctica del lenguaje con la expresión 'comprensión' no se ajusta al objeto filosófico "comprensión" (pensado como el nombre de un estado mental), la voz filosófica replicará que entonces se elimina la comprensión de los juegos de lenguaje, acusando a Wittgenstein de conductista. Por ello, cuando Wittgenstein sostiene que el significado es el uso, que el uso o la "aplicación" funciona como criterio de la comprensión, está alerta acerca de que esta observación es susceptible de múltiples apropiaciones filosóficas, el recurso retórico al que aludimos es extremadamente efectivo en este sentido, ayudando a anticipar, por ejemplo, que esta observación puede ser apropiada en términos de la tesis filosófica de un mecanismo (cerebral o de otro tipo, no viene al caso ahora) que produce las aplicaciones, tesis a la que Wittgenstein somete a crítica también con argumentos fuertemente concluyentes (ni necesario, ni suficiente, ver IF \# 149), de modo que va hilvanando su argumentación de acuerdo con las objeciones que le salen al paso.

Recapitulando un poco nuestros pasos: el embate a la "figura" agustiniana, que abre las Investigaciones se despliega como un ataque sin concesiones a la idea de un sujeto de la comprensión lingüística concebido como un "interior sin exterior", y a todo aquello que nos inclina a concebir el aprendizaje de la lengua materna al modo en que un extranjero aprende una segunda lengua (ver IF \# 32). Al respecto, Wittgenstein procura encontrar un mejor abordaje de lo que está involucrado en el orden de la comprensión lingüística procediendo en cierta manera como un "genealogista", es decir, retrocediendo en su respuesta hasta un ancestro de una naturaleza diferente, hasta el adiestramiento que remite a un conjunto de reacciones primitivas,

${ }^{39}$ Ver Fann, K. T., El concepto de filosofia en Wittgenstein, Madrid, Tecnos, 1997, pp. 127 y ss. 
como una manera de trastocar la tendencia a pensar el orden de la comprensión lingüística de una manera circular (Agustín, recordémoslo, rememoraba su aprendizaje de la lengua materna en términos de actos de "colegir" o "darse cuenta"). Esta estrategia apunta a transformar nuestra manera de entender los conceptos clave que dominan el discurso filosófico, lo que equivale, de hecho, a una destrucción de los mismos. ${ }^{40}$

Entre las observaciones positivas que así aparecen se destacan los conceptos de "juego de lenguaje" y de "forma de vida". Se trata de conceptos que no son fáciles de definir. El concepto de "juego de lenguaje" es presentado de distintas maneras, como "juegos por medio de los cuales aprenden los niños su lengua materna", como un recurso retórico argumentativo de Wittgenstein, que a veces nos pide imaginar un lenguaje primitivo que podría ser el lenguaje total de una tribu, a menudo usado como un objeto de comparación para poner de relieve ciertos aspectos de nuestro uso del lenguaje, y también como el "todo formado por el lenguaje y las acciones con las que está entretejido" (IF \# 7). Pero lo fundamental es que parece tratarse de un concepto pensado precisamente para tomar el relevo del problema de la esencia del lenguaje, ya que la presentación del concepto de juego de lenguaje está acompañada de una elucidación del concepto de "juego" como un concepto que carece de bordes nítidamente delimitados, aunque el carácter borroso de sus límites es reclamado como constitutivo del mismo (aparece aquí la noción de "parecidos de familia", ver IF \#\# 65, 66). En consecuencia, afirmar que el concepto de juego de lenguaje es esencial a la observación de la práctica efectiva del lenguaje equivale a afirmar que no hay una esencia del lenguaje. Algo semejante ocurre con el concepto de forma de vida, cuyo significado señala en dos direcciones. Una de ellas la podríamos parafrasear como "forma de la vida humana", se trata de las

\footnotetext{
${ }^{40} \mathrm{La}$ interpretación de Kripke es elocuente en este sentido. Al dividir de manera más acentuada los aspectos críticos y los elucidatorios del pensamiento de Wittgenstein, Kripke pudo presentar a Wittgenstein en dos pasos, en el primero, el desafío escéptico, negando la existencia de aquello que los filósofos denominan significado (concebido como una garantía del uso, como condiciones de verdad) y en el segundo, la solución escéptica, reconstruyendo el uso de la expresión 'significado' (su gramática) sin apelar a los presupuestos filosóficos cuestionados. Ver Kripke, Saul, Wittgenstein a propósito de reglas y lenguaje privado, Madrid, Tecnos, 2006, trad. de Jorge Rodríguez Marqueze.
} 
observaciones que aparecen a propósito del adiestramiento, de las reacciones presupuestas por la adquisición de la lengua a través del adiestramiento, por ejemplo, las que caracterizan a las reacciones del alumno como normales o anormales: "Este caso [el de quien continua una serie de una manera bizarra] sería semejante al de una persona que por naturaleza reaccionase a un gesto demostrativo de la mano mirando en la dirección que va de la punta del dedo a la muñeca en vez de en dirección a la punta del dedo" (IF \# 185, ver también \# 143) ${ }^{41}$ y que develan el carácter contingente del hecho de que haya lenguaje: "Y también aquí la capacidad de aprender de nuestro alumno puede quebrarse" (IF \# 143). En esta línea cabe ubicar también la célebre observación "Si un león pudiera hablar, no lo podríamos entender" (IF II, p. 511) y a la observación que indica que la posibilidad de comprensión depende del hecho de que quien recibe la instrucción reaccione continuando de manera independiente (ver IF \# 143). Por otra parte, la noción de forma de vida remite a la "forma de vivir", es decir, a las maneras sociales e históricas en las que se articulan las palabras y las acciones de los seres humanos: "La expresión 'juego de lenguaje' debe poner de relieve aquí que hablar el lenguaje forma parte de una actividad o de una forma de vida" (IF \# 23).

La introducción de estas nociones requiere algunas precisiones. La relación estrecha entre el entrenamiento y las formas de vida culturales, entre las formas de vida "naturales" y las formas de vida "sociales", para decirlo de acuerdo a nuestra distinción, intentaba obstaculizar una apropiación conductista o fisicalista de su pensamiento. Es que, bien considerado, el pensamiento de Wittgenstein señalaba más bien una eficacia en sentido contrario: desde las formas de vida sociales ya constituidas hacia la biología ("Lo que hay que aceptar, lo dado -decía Wittgenstein- son formas de vida"42), de ahí la ambigüedad radical del concepto de forma de vida. Es decir, en el momento de pensar en la adquisición de la lengua materna, Wittgenstein se topaba, o si se quiere, "se tropezaba", puesto que nunca llega a pensarlo

${ }^{41}$ En el Cuaderno marrón, Wittgenstein se refiere a las reacciones presupuestas por la enseñanza por medio de una analogía con el diferente entrenamiento que reciben distintas especies de animales, ver Cuadernos azul y marrón, Barcelona, Planeta de Agostini, 1994, p. 125.

42 Wittgenstein, Investigaciones filosóficas, p. 517 
plenamente, aunque lo indica todo el tiempo, con una forma de eficacia peculiar instalada en los propios juegos de lenguaje, en las formas de vida sociales: las mismas imponen sus requerimientos sobre los pequeños infantes, como veíamos en los fragmentos que acabamos de citar acerca de que la capacidad de aprender del alumno puede quebrarse, o en aquel que distingue una reacción normal y una anormal del aprendiz, que puede resultar en la inclusión o en la exclusión del aprendiz del juego de lenguaje en cuestión.

Ahora bien, tenemos así planteado el problema que suscitan las observaciones positivas que desgrana este fabuloso dispositivo de destrucción de los objetos filosóficos. Para poder abordar este problema tenemos que detenernos en uno de los parágrafos centrales de las Investigaciones, donde Wittgenstein expone su concepción del método que está practicando, es decir, de su estrategia filosófica:

Una fuente principal de nuestra falta de comprensión es que no vemos sinópticamente el uso de nuestras palabras. - A nuestra gramática le falta visión sinóptica. — La representación sinóptica produce la comprensión que consiste en 'ver conexiones'. De ahí la importancia de encontrar y de inventar casos intermedios. El concepto de representación sinóptica es de fundamental significación para nosotros. Designa nuestra forma de representación [unsere Darstellungform], el modo en que vemos las cosas. (¿Es esto una 'Weltanschaunng?) (IF \# 122)

Gordon Baker, inspirado en las observaciones de Friedrich Waismann en "Mi perspectiva de la filosofía" 43 ha realizado algunas observaciones cruciales para la comprensión de este fragmento. En su trabajo "Philosophical Investigations \#122, Neglected Aspects", ${ }^{44}$ Baker clarifica algunas de las dificultades que ofrece este fragmento, concentradas en la expresión 'representación'. Por una parte, clarifica la interpretación corriente de este fragmento, a la que denomina "Visión de vuelo de pájaro" y la cuestiona en algunos puntos cruciales. La visión de vuelo de pájaro comprende a la representación sinóptica como "un tipo particular de arreglo (Zusamenstellung)

${ }^{43}$ Waismann, Friedrich, "Mi perspectiva de la filosofía”, en Alfred Ayer, El positivismo lógico, Madrid, FCE, 1993.

${ }^{44}$ En Baker, Gordon, Wittgenstein's Method. Neglected Aspects. Essays on Wittgenstein, Oxford, Blackwell, 2004, editado por Katherine Morris. 
de descripciones de "el uso de nuestras palabras"' (Baker, p. 25), es decir, una organización de las reglas gramaticales que las hace susceptibles de ser aprendidas como un todo, una representación sinóptica consistiría entonces en "conjuntos de reglas inspeccionables que constituyen explicaciones completas de cómo usar las "palabras de nuestro lenguaje" ${ }^{45}$. Esta concepción de la representación sinóptica, constata Baker, habilitaría una forma de filosofía sistemática, de manera que aunque Wittgenstein haya "tratado los problemas particulares como enfermedades (IF \# 255) y aplicado terapias particulares diversas para hacerlos desaparecer (IF \# 133), su ideal de construir representaciones sinópticas parecería indicar una inclinación hacia una filosofía más sistemática". ${ }^{46}$

Baker encuentra en una versión más temprana de estas ideas, la que está presente en el texto conocido como Big Typescript, los elementos necesarios para impugnar esta concepción de la representación sinóptica. La clave de su impugnación consiste en poner el foco en los efectos de dichas "representaciones", los cuales consisten básicamente "en romper nuestra servidumbre hacia las analogías absorbidas en las formas de expresión de nuestro lenguaje". ${ }^{47} \mathrm{La}$ lectura alternativa propuesta por Baker descansa así en dos supuestos, por un lado, que no hay ninguna restricción acerca de la forma que puede tomar una forma de representación sinóptica, ${ }^{48}$ por un lado, y por el otro que el término 'representación' se emplea para exhibir aspectos “del uso de las palabras". ${ }^{49}$ De acuerdo con Baker, esta interpretación permite

\footnotetext{
45 Ibid., p. 25.

46 Ibid., pp. 26-27.

${ }^{47}$ Ibid., p. 31.

48 Como evidencia en este sentido se puede señalar que la concepción agustiniana puede funcionar en ciertos contextos como una explicación del uso de los sustantivos (ver IF \# 5) o bien que Wittgenstein considera que la expresión "Sólo tú puedes saber si tuviste la intención” a la que cuestiona de distinta maneras como una representación desorientadora de la gramática de la manifestación de los estados internos, grafica sin embargo correctamente un aspecto de la misma, que quien manifiesta un estado interno no puede dudar del mismo, y en consecuencia podría ser utilizada para enseñar a alguien el significado de 'intención'. ver IF \# 247.

49 Ver Baker, op. cit., pp. 31-32.
} 
reconocer que "hay una estrategia general exhibida en todas las diversas terapias y que la posibilidad de dominarlas y transferirlas a nuevos problemas le da sustancia a la pretensión de que el correcto tratamiento de cada problema echa luz sobre el tratamiento de todos (Zettel \# 465)". ${ }^{50}$

Hay dos aspectos de esta caracterización de la estrategia de las Investigaciones que nos parecen destacables. En primer lugar, que en contraste con la concepción de la "visión de vuelo de pájaro" de la representación sinóptica, la interpretación de Baker no instaura una "herida" entre la práctica del lenguaje y la práctica filosófica, ${ }^{51}$ sino una diferencia, que, en contraste con la herida filosófica, es reabsorbida en el interior de la práctica de los juegos de lenguaje. En este sentido cabría explorar la relación de la corrección de una representación perspicua con la "justeza" (justesse) de una intervención filosófica como la concibe Althusser, es decir, como la instauración de una distancia con una práctica determinada que revela ser, a fin de cuentas, una distancia nula, que se anula, pero que no por eso deja de producir efectos en la práctica sobre la que interviene, al contrario, la toma de distancia es efectiva en virtud de que acaba integrándose en la práctica sobre la que interviene, produciendo modificaciones en la misma. ${ }^{52}$

Por otra parte, nos interesa detenernos por un momento en el diagnóstico sobre la "fuente" de los problemas filosóficos que subyace a esta concepción de la estrategia filosófica. Los problemas que ataca la representación sinóptica son concebidos como el efecto de la tiranía que un sistema de expresión ejerce sobre nosotros, como "el embrujo de nuestro entendimiento por medio de nuestro lenguaje" (IF \#109), por el hecho de que "[]os aspectos de las cosas más importantes para nosotros están ocultos por

\footnotetext{
${ }^{50}$ Ibid., p. 33.

51 "Las descripciones analógicas de la gramática están en el mismo nivel que las analogías no examinadas que ellas intentan reemplazar disolviendo problemas filosóficos particulares." (Ibid., p. 34).

52 Ver Althusser, Louis, Curso de filosofía para cientificos, Barcelona, Planeta-de Agostini, 1985, trad. de A. Roies. Véase también mi trabajo "Presentación de Louis Althusser: La internacional de los buenos sentimientos", en Demarcaciones, $\mathrm{N}^{\circ} 4$, para un tratamiento detallado de este problema.
} 
su simplicidad y cotidianeidad." (IF \# 129), de modo que, comenta Baker, "podemos liberarnos de la esclavización del ideal reconociéndolo como una figura, y encontrando su fuente; a menos que encontremos la imagen concreta que lo hace surgir (Urbild), no podemos liberarnos de su aspecto confundente". 53

Concordamos plenamente con esta caracterización de la estrategia filosófica de Wittgenstein, nos parece que la misma responde a lo esencial de su manera de abordar los problemas filosóficos, y en particular al rasgo de su argumentación sobre el que hemos llamado la atención: su extrema sensibilidad a la posibilidad de que una observación que produce un efecto en un contexto determinado produzca un efecto muy distinto en otro contexto.

Sin embargo, la caracterización de la estrategia realizada a través del concepto de representación sinóptica no nos ayuda a pensar la persistencia, la insistencia de los problemas filosóficos, o lo hace sólo de una manera muy insatisfactoria. En efecto, los problemas filosóficos son achacados al embrujo de nuestro pensamiento por nuestras formas de expresión, por ejemplo "Y hacemos aquí lo que hacemos en miles de casos similares: Puesto que no podemos indicar una acción corporal que llamemos señalar la forma (en contraposición, por ejemplo, al color), decimos que corresponde a estas palabras una actividad espiritual. Donde nuestro lenguaje hace presumir un cuerpo y no hay un cuerpo, allí, quisiéramos decir, hay un espíritu" (IF \# 36). A la base de este y otros enredos filosóficos, y de la seducción del discurso filosófico, encontramos en Investigaciones una explicación en términos de ilusión (\#\# 96, 97, 362), exigencia (\# 107), prejuicio (\#\# 108, 109, 131, 340), tentación (\# 39), inclinación (\#\# 73, 109), embrujo (\# 109), superstición (\# 110), y de reacciones espontáneas que son atribuidas "por naturaleza" a uno u otro individuo (\# 185).

En este punto encontramos que Wittgenstein se queda corto en relación con los recursos que su pensamiento ofrece. Ya que, a expensas de un reconocimiento diversificado de la eficacia propiamente social de las formas de vida, nuestro filósofo parece apoyar la comprensión de la singular persistencia de los problemas filosóficos en el otro vector del concepto de forma de vida

${ }^{53}$ Baker, op cit., p. 33. 
que distinguimos, el de las reacciones a continuar de manera independiente. De esta manera, Wittgenstein parece hacer descansar lo "espontáneo" del embrujamiento filosófico, la manera "natural" en que nos seducen y nos envuelven los planteos de la filosofía, sobre un vector cuya dominante es individual y natural. Si bien la correlación entre formas de vida naturales y formas de vida histórico-sociales matiza esta conclusión, ello no cambia el lugar en que el énfasis aparece colocado. Esto nos parece un límite de su pensamiento, aunque no un límite absoluto, ya que en las Investigaciones encontramos varios elementos que apuntan en otra dirección. Por una parte, una acentuada sensibilidad para reconocer los requerimientos que los juegos de lenguaje imponen sobre los pequeños cachorros humanos, por medio de los conceptos de adiestramiento y de forma de vida, como aquello que posibilita y condiciona a la vez su inserción, y la modalidad de la misma, es decir por medio de un vector que va de la sociedad a la biología. ${ }^{54}$ La elucidación de la gramática de las diferentes "atribuciones semánticas" ('comprender', 'poseer un concepto', 'seguir una regla', etc.) pone de manifiesto una trama de requerimientos semejante, cuyos efectos tienden a la normalización de los hablantes, o mezclando términos alhusserianos y wittgensteinianos, a la sujeción de los individuos a la práctica del juego, para cualquier practicante de un juego de lenguaje. ${ }^{55}$ En otros términos, el diagnóstico dominante acerca de la fuente de los problemas filosóficos nos parece operar como un obstáculo para ciertas posibilidades de elaboración conceptual que parecen estar disponibles en las Investigaciones y en otros textos del austriaco. Por ejemplo, en el Cuaderno azul Wittgenstein pensó la persistencia de la filosofía remitiéndola a la insatisfacción con una convención gramatical de parte del filósofo, por medio de la analogía con alguien que estuviera inclinado a cuestionar el uso del nombre "Devonshire" para el territorio convencionalmente delimitado por ese distrito, insistiendo en que el mismo corresponde "realmente" a una

\footnotetext{
${ }^{54}$ Ver el tratamiento de este problema en Althusser, Louis, Psicoanálisis y ciencias humanas. Dos conferencias, Buenos Aires, Nueva visión, 2014, trad. de P. Betesh, pp. 80 y ss. 55 Ver la "solución escéptica" en Kripke, op. cit., y Kusch, Martin, A Sceptical Guide to Meaning and Rules. Defending Kripke's Wittgenstein, Montreal, McGill-Queen's University Press, 2006.
} 
región delimitada de otro modo. ${ }^{56}$ Esta concepción de lo que impulsa hacia la filosofía, que fuera retomada luego por Morris Lazerowitz, ${ }^{57}$ tenía la virtud de colocar lo que impulsa hacia la filosofía en terreno práctico, o mejor dicho en terreno político, es decir, polémico, contradictorio, aunque el intento estuviera dominado por una concepción más bien rudimentaria, en términos de la relación entre el individuo (filósofo) y la sociedad (gramática). Por último, el diagnóstico de la emergencia de los problemas filosóficos como efecto de la transgresión de los límites de un juego de lenguaje para aplicarlo a otros (por ejemplo, la aplicación del modelo "nombre-designación-definiciones ostensivas" al lenguaje de las sensaciones), puede verse como la traslación de una analogía por parte de un individuo en función de que un aspecto se impone como prevalente, pero también se puede pensar que este comportamiento individual es un efecto de la intervención de un juego de lenguaje sobre otro, de lo que resultaría que esta intervención impone sus propios requerimientos y produce que prevalezcan algunos aspectos como un efecto suyo. En otros términos, Wittgenstein reconoce un territorio que es el de la ideología, sin ceder a sus evidencias, pero sin lograr pensar el mecanismo que produce estos efectos. ${ }^{58}$

Recapitulemos, para concluir, estas limitaciones de la filosofía de Wittgenstein que parecen encontrar un paralelo con algunas dificultades que han sido señaladas en la propuesta de Derrida. Por una parte, como lo ha destacado François Wahl, Derrida enfrentó una tensión semejante a algunas de las que encontramos al presentar el concepto wittgensteiniano de representación sinóptica, ya que conceptos como gramma, traza, différance y otros

\footnotetext{
${ }^{56}$ Wittgenstein, L., Cuadernos azuly marrón, op. cit., p. 90.

${ }^{57}$ Ver el comentario de diversas concepciones de la terapia filosófica, incluida la muy sugerente de Lazerowitz, en Engel, S. Morris, Wittgenstein Doctrine of the Tyranny of Language. An Historial and Critical Examination of his Blue Book, La Haya, M. Nijhoff, 1975. ${ }^{58}$ En palabras de Dominique Lecourt: "la sospecha que él ha levantado justamente contra cualquier interpretación-justificación de estos juegos como tentativas de borrar y finalmente negar la realidad sui generis de estos juegos, subordinándolos a alguna instancia psicológica fisiológica o metafísica dada previamente, parece extenderse a sí mismo su impacto contra cualquier intento de dar cuenta del increíble impacto con el que se imponen tales interpretaciones" (Lecourt, D., La philosophie sans feinte, p. 28).
} 
corren el riesgo, en virtud de la arquitectura del discurso derrideano, de convertirse en el principio de una metafísica. ${ }^{59}$ Por otra parte, un concepto como el de "fonocentrismo", en la medida en que intenta dar cuenta de la metafísica como un efecto inducido por la escritura fonética, nos parece estar aquejado de un riesgo semejante al que presentan los conceptos con los que Wittgenstein intenta dar cuenta de la emergencia del discurso filosófico. No queremos indicar que se trate de limitaciones absolutas, sino de la irresolución de una tensión en la que se mueve un pensamiento. Así, Derrida da un paso que también podemos encontrar en las Investigaciones, al reconocer que la metafísica funciona como una especie de "ilusión trascendental", ${ }^{60}$ es decir, que no se trata de un efecto contingente, como lo sería la ilusión de un individuo, ya que, por ejemplo, cuando nos las vemos con la reducción de la exterioridad del significante, o con la representación del lenguaje como “expresión”, no se trata de: “...un prejuicio accidental, sino de una suerte de trampa (leurre) estructural, lo que Kant habría llamado una ilusión trascendental". ${ }^{61}$ Poco después Derrida añade que esta "ilusión trascendental" o "trampa estructural" “...se modifica según los lenguajes, las épocas, las culturas" y que si bien la metafísica occidental es una poderosa sistematización de la misma, no habría que apresurarse a otorgarle exclusividad. ${ }^{62}$ En este concepto de la trampa estructural se anuda el problema de la eternidad de la ideología y del inconsciente (y de la metafísica). A partir de Wittgenstein pudimos pensar estos fenómenos bajo la forma de condicionales contrapuestos. Allí donde una posición trascendental dice "si no hubiera una función sintética de la subjetividad no habría lenguaje", Wittgenstein responde, "si no practicáramos juegos de lenguaje, no nos manifestaríamos como sujetos", poniendo de manifiesto, no sin tensiones y dificultades, como hemos visto, la dimensión de los requerimientos, exigencias o demandas propiamente

${ }^{59}$ Cfr. Wahl, François, ¿Qué es el estructuralismo? Filosofía, traducción de Andrés Pirk. Buenos Aires, Losada, 1975, pp. 192 y ss.

${ }^{60}$ En otros trabajos hemos explorado un aspecto análogo en el pensamiento de Wittgenstein a propósito de problemas como la ceguera y visión de aspectos fulgurantes de las figuras ambiguas, la ceguera para el significado, etc. Véase el ya citado "Materialismo, ideología y juegos de lenguaje".

${ }^{61}$ Jacques Derrida, "Sémiologie et grammatologie. Entretien avec Julia Kristeva", en su Positions, Paris, Minuit, 1972.

62 Idem. 
sociales que los juegos de lenguaje y las formas de vida dirigen a sus practicantes. Con Althusser pudimos comenzar a comprender, a través del concepto de modo de producción, la manera en que estas demandas se entrelazan con la reproducción de la vida social, concebida como un proceso contradictorio, es decir, como lucha de clases.

Para concluir, queremos insistir una vez más en que la filosofía que encontramos en las Investigaciones es pensada como una actividad, como una filosofía atenta hacia los diversos usos de las palabras, es decir, hacia el exterior denegado de la filosofía, esto es, hacia los distintos juegos de lenguaje, o sea, hacia las distintas prácticas, instituciones y costumbres donde dichas palabras encuentran sus propósitos y su eficacia. En este sentido, no se trata de una nueva filosofía, de una nueva doctrina filosófica, sino de "una nueva práctica de la filosofía". Sin embargo, estas prácticas, este exterior denegado de la filosofía, que Wittgenstein registra a su modo, aparecen, en su presentación dominante -que naturalmente posee excepciones, algunas de ellas aparecieron en nuestro trabajo- bajo una forma idealizada, sólo así se puede sostener: "la claridad a la que aspiramos es en verdad completa. Pero esto sólo quiere decir que los problemas filosóficos deben desaparecer completamente" (IF \# 133). Tendremos que esperar hasta Sobre la certez $a^{63}$ para encontrar el inicio de una revisión y el registro mucho más decidido de las tensiones que ocurren en el seno mismo de la práctica lingüística, efecto de los procesos de unificación y sistematización, ahora más decididamente reconocidos, de los juegos de lenguaje y sus evidencias, como así también un énfasis mucho más marcado sobre los efectos de los juegos de lenguaje en la normalización de los individuos.

${ }^{63}$ Wittgenstein, Ludwig, Sobre la certeza, Barcelona, Gedisa, 1991, compilado por G. E. M. Anscombe y G. H. von Wright, trad. de Josep Lluís Prades y Vicent Raga. 